Kansas State University Libraries

New Prairie Press

\title{
MULTIVARIATE STATISTICAL ANALYSIS OF AVIAN INDEX OF BIOTIC INTEGRITY
}

\author{
Bahman Shafii \\ William J. Price \\ Norm Merz \\ Dwight Bergeron
}

See next page for additional authors

Follow this and additional works at: https://newprairiepress.org/agstatconference

Part of the Agriculture Commons, and the Applied Statistics Commons

\section{(c) $(1) \Theta \Theta$}

This work is licensed under a Creative Commons Attribution-Noncommercial-No Derivative Works 4.0 License.

\section{Recommended Citation}

Shafii, Bahman; Price, William J.; Merz, Norm; and Bergeron, Dwight (2012). "MULTIVARIATE STATISTICAL ANALYSIS OF AVIAN INDEX OF BIOTIC INTEGRITY," Conference on Applied Statistics in Agriculture. https://doi.org/10.4148/2475-7772.1025

This is brought to you for free and open access by the Conferences at New Prairie Press. It has been accepted for inclusion in Conference on Applied Statistics in Agriculture by an authorized administrator of New Prairie Press. For more information, please contact cads@k-state.edu. 
Author Information

Bahman Shafii, William J. Price, Norm Merz, and Dwight Bergeron 


\title{
MULTIVARIATE STATISTICAL ANALYSIS OF AVIAN INDEX OF BIOTIC INTEGRITY
}

\author{
Bahman Shafii and William J. Price \\ Statistical Programs, College of Agricultural and Life Sciences, University of Idaho, Moscow, Idaho \\ Norm Merz \\ Fish and Wildlife Department, Kootenai Tribe of Idaho, Bonners Ferry, Idaho \\ Dwight Bergeron \\ Montana Fish, Wildlife and Parks, Kalispell, MT
}

\begin{abstract}
The Index of Biotic Integrity (IBI) is a multi-metric index designed to measure the changes in ecological and environmental conditions as affected by human disturbances. Hence, IBI is used in practice to detect divergence from biological integrity attributable to human actions. The incorporation of biological attributes is often done at both the individual and higher level assemblages. The objective of this paper is to demonstrate the construction and statistical evaluation of a multi-metric Avian Index of Biotic Integrity (A-IBI). Canonical correlation analyses are utilized to select pertinent avian metrics as impacted by vegetation and hydrology variables. The resulting avian metrics are then ranked, according to a pre-specified scale of human disturbance, and the A-IBI scores are subsequently computed. The multivariate models as well as the final A-IBI scores are statistically validated, both spatially and temporally, using independent data sets. The techniques are demonstrated using five years of avian survey conducted on the terrestrial environments of the Kootenai River watershed in Northern Idaho and Northwestern Montana.
\end{abstract}

\section{Introduction}

The Index of Biotic Integrity (IBI) is considered to be a multi-metric index used to accurately reflect changes in ecological complexity with human disturbance (Kerans and Karr, 1994). IBI is often constructed to detect divergence from biological integrity attributable to human action. Hence, it should incorporate biological components sensitive to a range of human activities. The incorporation of biological attributes needs to be done at both the individual and higher level assemblages such as guilds (Karr, 1999). Additionally, the selected biotic metrics should be chosen based on biological relevance, sensitivity to anthropogenic impact, and cost effectiveness (Andreason et al., 2001). 
The traditional IBI analyses consider univariate solutions for biological variables and selected site characteristics. This often includes parametric and nonparametric correlation analyses between a set of biological metrics and corresponding environmental site index or site characteristic scores.

In many cases, however, the aforementioned approach may lead to low correlations and no discernible patterns or correspondence with disturbance measures. Ecological investigations often involve a multimetric ecosystem with multiple community responses measured at varying dimensions. Hence, the current analyses will consider a multivariate approach.

The objective of this study is to present the construction and evaluation of a multi-metric Avian Index of Biotic Integrity (A-IBI) using the multivariate canonical correlation. Applications will be demonstrated with reference to five years of bio-monitoring avian surveys conducted on the terrestrial environments of the Kootenai River watershed in Northern Idaho and Northwestern Montana.

\section{Methods of Analysis}

\section{IBI Development Flow Charts}

In general, IBI construction starts with defining the human impact or disturbance level based on abiotic factors for a selected number of sites. The site characteristics are then correlated with potential biotic variables to identify important biological variables. The expected direction of biological variables relative to disturbance are then determined and rated (ranked) on a nominal scale. The sum of these ranks is subsequently used to form the desired IBI scores. Validation and/or verification often follows the construction of the initial IBI model. The traditional flow chart for the IBI construction is depicted in Figure 1a.

In some application of IBI methodology, principle component analysis (PCA) is employed to identify important site characteristic variables (see for example Kerans and Karr, 1994). We expand on that idea, and propose using canonical correlation analyses to identify both important biological as well as site characteristic variables. The procedure is further improved by using a common human based disturbance scale for the site characteristic variables, and determination of the expected direction of biological variables based upon the sign of correlation with these standardized site scores. The enhanced IBI construction flow chart is given in Figure 1b. Note the application of canonical analyses differentiating the two approaches. 


\section{Source and Description of the Data}

The project data components included both biological/ metrics (avian species and invertebrate family data along with those taxa assigned into guild and calculated into community diversity metrics) as well as site characteristics (hydrology and vegetation) variables. Only the avian data and corresponding site characteristics are utilized here. The invertebrate data will be treated in the same manner in subsequent IBI analyses and reports.

Avian data were collected using a 3-minute point count methodology in which a single trained observer recorded all birds seen or heard during a specified time period. Point counts were replicated three times per site during the breeding season (late May - mid July). For this analysis, data from 2007, 2008, 2009 were used, retaining observations with distance $\leq 50 \mathrm{~m}$, and omitting species data recorded as "fly over". Flyovers were recorded when a bird(s) flew through the plot, but it was determined that it was not using the habitat within the plot. Species level data for each site - year combination were aggregated over the 3 replications/ year. If a site-year combination did not have a full 3 replications per year, that site-year combination was dropped from the analysis. After the data were aggregated over the site-year combinations, diversity indices and the relative abundance of guild classes were calculated. The three annual sets of avian metrics were then averaged for each site-year combination to give one value per metric for the 3-year period set at each site $(n=58)$.

Avian diversity metrics considered were:

- $\quad$ Richness - Hill's Richness, $\mathrm{N}_{0}$ (Hill 1973)

- $\quad \mathrm{N}_{2}$ - Hill's Diversity (Hill 1973)

- $\quad \mathrm{N}_{2} / \mathrm{N}_{1}-$ Hill's Evenness (Hill 1973)

- E-Pielou's Evenness Index (Pielou 1977)

- $\ln ($ Count $)-\log$ of abundance

Avian species were classified into four guild types:

- Migratory status - Five migratory status classes were used including:

- Resident or year-long inhabitant;

- Short Distant Migrant - species that winter in southern United States;

- Mexico- species that winter in northern to central Mexico;

- Neotropical- species that winter in southern Mexico through central America;

- Long Distance Migrant- species that winter in South America 
- $\quad$ Nesting status - Four nesting status categories were implemented:

- Obligate or species that $90 \%$ of their reproduction occurs within riparian habitats;

- Dependant - or species that $60 \%$ of their reproduction occurs within riparian habitats;

- Marsh- marsh obligate birds;

- Neutral or generalist birds that reproduce within a number of habitat types.

- Trophic status - The avian complement (all species observed at a point) was divided into three classes of trophic level based on the main diet during the sample period:

- Primary consumers or those species utilizing vegetative component;

- Secondary consumers or those species utilizing first level consumers including insects;

- Tertiary consumers or predators foraging on other vertebrates such as birds and small mammals and fish.

- Disturbance tolerance - Four categories were established in reference to disturbance regimes:

- $\quad$ Sensitive species generally are eliminated with disturbance;

- Tolerant species maintain population levels within disturbance regimes possibly with slight decline;

- Neutral species are unaffected by disturbance; They neither increase or decrease.

- Beneficial applies to species whose population levels increase with disturbance.

Life cycle information was gleaned from data bases such as Birds of North America (Cornel Lab of Ornithology), Northern Prairie Wildlife Research Center (USGS), The Avian Science Center (University of Montana, Missoula MT) and professional experience with Montana Fish, Wildlife \& Parks.

Observed counts were then summed over replications to give one value per species - site - year combination. Site-year specific relative abundances for each guild type class were computed. Annual 
relative abundance values in each site were averaged to provide one value per guild type class. The Trophic Status guild category was omitted from analyses because the majority of data were classified into two sub-categories, i.e. primary and secondary consumers, and little information was gained from them. A total of 13 guild classes were considered in the subsequent analyses.

In addition, avian Key Ecological Functions (KEF's) (Marcot and Vander Heyden 2001) were utilized as potential biotic variables. Fifty KEF components were used to define two composite metrics: Annual composite values were averaged for each site to give one set of composite KEF metrics per site.

- $\quad$ KEF_Avg - The average number of functions per species.

- $\quad$ KEF_Redund - The number of redundant functions per site.

The hydraulic variables considered were:

- WD_Avg - Average of water depth site scores across flood return intervals.

- SS_Avg - Average of shear stress site scores across flood return intervals.

- FD_Avg - Average of flood duration site scores across flood return intervals.

- Combined_Avg - Average of the above hydraulic site scores.

- $\quad$ FFZ - Inundation frequency site score.

- OAHD-Average of all individual hydraulic variables related site score.

Hydraulic scores were based on the proportional difference between modeled historic vs current situations at each site under a suite of flood return intervals $(1,2,5,10,25,50$-year flood return intervals).

The vegetation variables considered were:

- $\quad$ Sum of Struct - Weighted average of structure site scores based on the number of structural layers, eg. Canopy, etc.

- Sum of Tree - Weighted average Sum of tree site scores based on the percentage of canopy cover provided by riparian associated tree species

- Sum of Shrub - Weighted average Sum of shrub site scores based on the percentage of canopy cover provided by riparian associated shrub species

- $\quad$ Sum of Weed - Weighted average Sum of weed site scores based on the percentage of canopy cover of noxious weeds

- $\quad$ Sum of RCG - Weighted average Sum of reed canarygrass (RCG) site scores based on the percentage of RCG canopy cover.

- Sum of Avg Rip - Simple average of the above riparian site scores

Due to the heterogeneity of the sites, the scores were weighted by the proportion of the respective cover type.

It is important to note that within the study area, the hydroelectric Libby dam is the primary and predominant source of human disturbance. Its main effect is to regulate and mitigate flooding events 
through controlled water releases. These management activities directly affect and change the riparian vegetation along the river. These include changes in species composition as well as succession sequences. Hence, the aforementioned vegetation variables were included to provide a relevant and encompassing measure of human disturbance.

Each hydrology and vegetation characteristic was scored with regard to human impact on a scale from 1 to 10, where 1 and 10 represent high and low impact, respectively. Scoring of hydrology and vegetation characteristics was provided by the project personnel. Scoring provides a standardized scale of disturbance, which will provide the independent variables in subsequent construction of the IBI scores.

Point count locations were selected through a random process. Initially, the Kootenai River was segmented into eight arbitrary reaches extending from Libby Dam to the Canadian border. Within each reach, sample sites were randomly generated throughout the 500-year floodplain using ArcInfo GIS (ESRI 2002). This sample was reduced by applying selection filters, such as land ownership, access, safety, less than 5 habitat types within $50 \mathrm{~m}$, and distribution throughout the reach. Once a sample site was selected from on-the-ground verification, all random points within $150 \mathrm{~m}$ were excluded from consideration to maintain independence of the point count samples. In addition, land cover classification was considered to ensure reasonable representation of land cover classes throughout the reach. Sites with flood return interval, FRI, $\leq 50$ years were retained, and sites with fewer than three replications per year were omitted. A flood return interval of less than 50 years was selected as this provides the most information on the regulatory effects caused by Libby dam, which was constructed 40 years ago. Although longer interval flood events do occur, they are infrequent and do not consistently capture the dynamic regulatory effects of the dam on the floodplain. A total of $n=58$ avian sites were represented in the final IBI analyses. Figure 2 represents a topographical map of the avian sites within the specified study area.

\section{Multivariate Analysis}

Given a multivariate data set, e.g. avian community responses, PCA may be utilized to reduce the dimension of the data by determining one or more linear combinations of the responses (axes) that account for the largest proportion of variability in the data. The objective is to retain as few axes as possible while explaining the majority of the data variability (Morrison, 1976; James and McCulloch, 1990). The PCA axes represent lurking, subject related, underlying factors, while the coefficients (loadings) of these axes convey information on the relative importance of individual variables. These loadings will in turn provide a means for variable selection.

Similarly, given two multivariate data sets, such as avian diversity metrics and hydrology site score variables, PCA can be utilized to assess the association between the data sets. However, canonical correlation carried out on both data sets simulataneously, extends the PCA by computing correlation between the corresponding axes of the data sets (or canonical correlation). Hence, canonical correlation 
analyses allow for investigating multivariate relationships, as well as providing a means for selecting both biological and site related variables concurrently.

Five separate scenarios were considered relating each set of the avian biological variables (guild and diversity) to that of the site characteristics (hydrology and vegetation), as well as an integrated model relating both sets of biological variables to the site score variables:

\begin{tabular}{|c|c|c|}
\cline { 2 - 3 } \multicolumn{1}{c|}{} & Hydrology & Vegetation \\
\hline $\begin{array}{c}\text { Avian } \\
\text { Metrics }\end{array}$ & Model 1 & Model 3 \\
\hline $\begin{array}{c}\text { Avian } \\
\text { Guilds }\end{array}$ & Model 2 & Model 4 \\
\hline \multicolumn{1}{|c|}{ Model 5: Integrated } \\
\cline { 2 - 3 } & \multicolumn{2}{c|}{}
\end{tabular}

Each scenario was initiated with a full suite of respective biological and site score variables (full models). Subsequently, reduced models were constructed using backward elimination of variables in each respective full model while maintaining model integrity and canonical correlation $\geq 0.65$. The generic forms of the four reduced models are given below.

\section{Model 1:}

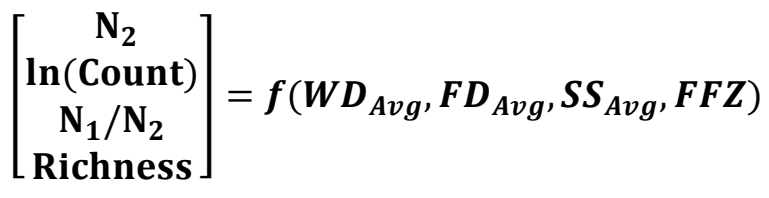

\section{Model 2:}

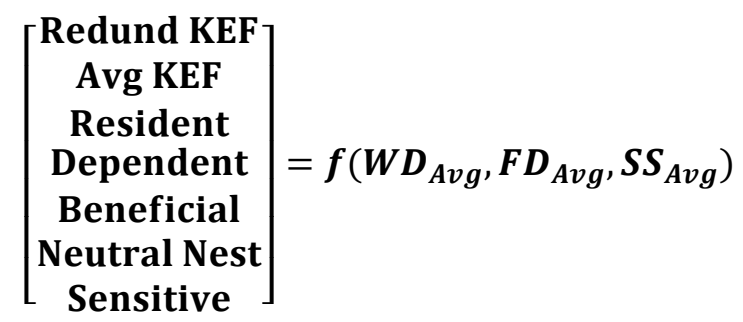


Model 3:

$$
\left.\left[\begin{array}{c}
\mathrm{N}_{2} \\
\ln (\text { Count }) \\
\mathrm{N}_{1} / \mathrm{N}_{2} \\
\text { Richness }
\end{array}\right]=\text { f(Struct, RCG, RIP }\right)
$$

Model 4:

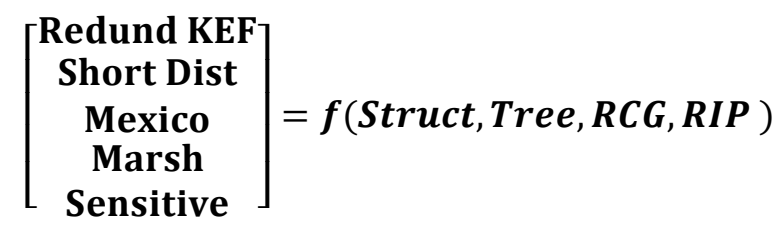

Reduced models were assessed using multi-metric canonical regression,

$$
\mathrm{Y}^{i}{ }_{\text {Avian }}=\mathrm{b}_{0}+\mathrm{b}_{1} \cdot \mathrm{X}_{\text {Site }}^{i}
$$

where $\mathrm{Y}_{\text {Avian }}^{i}$ is the $\mathrm{i}^{\text {th }}$ canonical axis of avian measures, $\mathrm{X}_{\text {Site }}^{i}$ is the $\mathrm{i}^{\text {th }}$ canonical axis of site scores, and $\mathrm{b}_{0}$ and $b_{1}$ are regression coefficients. Canonical regression provided numerical and graphical information on the multivariate relationships present.

Reduced models were further assessed through multivariate multiple regression models and diagnostics. For brevity, these results are omitted from the current presentation.

The final integrated model took the generic form:

\section{Model 5:}

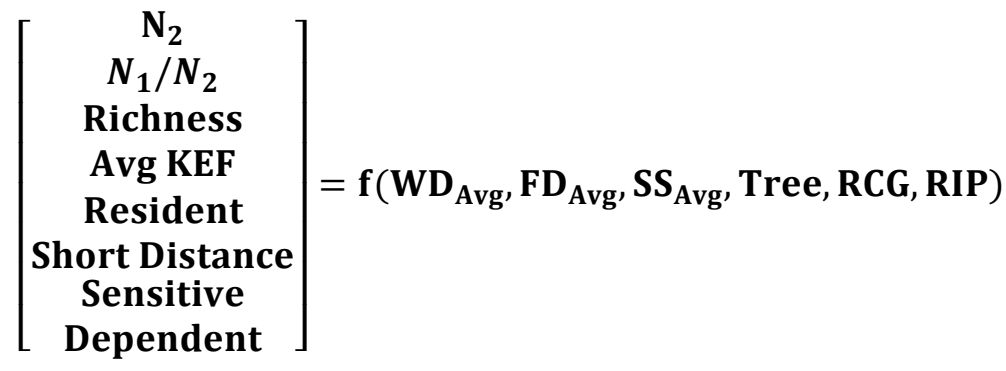

The model was estimated using weighted canonical correlation analysis. Avian abundance was used as weight to mitigate the heterogeneity of site with regard to abundance of bird species. This also improved the canonical correlation structure between the biological and site score characteristics. Notice that the final model encompasses eight avian diversity and guild metrics that were subsequently utilized in the construction of avian IBI scores. 


\section{IBI Construction}

In order to construct the avian index of biotic integrity (A-IBI), the relationships of the selected biological variables with disturbance must be assessed. The question posed: does the variable value increase or decrease with disturbance? Kerans and Karr (1994) suggest using the "expected direction". While this is a viable option, it introduces certain level of subjectivity into the problem possibly leading to inconsistency, especially if the number of selected characteristic variables is large. In this study, the signs of the correlations between the biological variables and the standardized site scores were used to allow for direct assessment of "direction".

The biological variables were ranked and subsequently scored on the following ordinal scale: $1=$ very low integrity; $3=$ low integrity; $5=$ moderate integrity; $7=$ high integrity; $9=$ very high integrity using the quintiles of the variable distributions. Within each site, the individual component IBI values were then summed to form an overall IBI score. Hence A-IBI is useful for relative site to site comparisons as pertinent to avian guild assemblage and diversity metrics. It is not appropriate for determining absolute habitat or ecological condition.

\section{IBI Validation and Verification}

In order to avoid introducing inherent functional relatedness (circularity) into the IBI model development process, the final model should be applied to, or validated with, independent data sets. Both spatial and temporal validations are recommended (see for example, Karr, et. al, 1987, US EPA, 2002) to ensure model adequacy. Validation and verification assessments provide a means to evaluate the quality and reliability of the IBI scores. Verification should include ground truthing with sites having known levels of impact and association with site scores, whereas validation should be evaluated at different spatial/temporal scales.

The 2006 and 2010 avian data were used for the purpose of statistical validation. The validation process for each year (as well as the average of both years) encompassed data component comparison, canonical correlation validation, and bootstrap simulation. Thirty-one additional avian sites, not included in the original A-IBI model construction process, were also employed for the purpose of IBI score verification.

All statistical computations and graphics were carried out using the SAS (2009) software.

\section{Empirical Results}

\section{Multivariate Analysis and Model Assessment}

The four model scenarios defined earlier relating avian responses to site score variables were assessed using canonical correlation methods. Starting with a full model in each case, a backwards elimination process was employed as described above. All models produced strong primary correlations 
greater than 0.65 and showed only one significant primary canonical axis (first axis for all models: $\mathrm{p}<$ 0.0001). Specific results for the first axis of the final reduced models are given in Table 1. Model 1, relating avian metrics and hydrologic scores, produced a canonical correlation of 0.67 . The avian components selected included diversity, evenness and abundance measures. The hydrologic components selected were overall measures of inundation and those related to water depth, shear stress and flood duration. The corresponding avian metrics - vegetation scenario, Model 3, produced the same avian metrics in addition to the vegetative scores for structure, reed canarygrass and riparian qualities $(\mathrm{R}=0.65)$. The remaining scenarios corresponding to avian guild responses, Models 2 and 4, gave canonical correlations of 0.71 and 0.75 , respectively. The selected avian guild responses varied and included KEF measures, as defined above, and nesting measures, as well as disturbance, migration and tolerance values. In all cases the standardized coefficients were deemed strong enough to warrant retention in the respective models.

Both hydrologic models, 1 and 2, had the site score variables WD_Avg, FD_Avg, and SS_Avg in common, while the vegetative models, 3 and 4, both selected for the variable score set of Struct, RCG, and RIP. Given the strength of the four model scenarios and their commonalities among site scores, a fifth integrated model, encompassing all selected avian measures and the corresponding hydrologic and vegetative score measurements, was assessed using the same backwards selection process. In this case, the model was estimated using avian species abundance as weight to mitigate the heterogeneity of sites with regard to abundance of bird species.

The final results for this integrated model are shown in Table 2. One canonical axis was highly significant and accounted for approximately $70 \%$ of the data variability. The canonical correlation along this axis was very strong at 0.89 . The remaining axes, while moderately significant, were considered to be of limited importance for the goal of IBI construction. Considering the primary axis, the final integrated model retained three hydrologic score variables: WD_Avg, FD_Avg, and SS_Avg, as well as the vegetation score variables: Tree, RCG, and RIP. Avian responses included measures for diversity, evenness, KEF, migration status and nesting status, with the standardized coefficients showing the relative and contrasting importance of Richness and Evenness $\left(\mathrm{Hill}_{2}\right)$. Overall, this primary axis shows a strong multivariate relationship (Figure 3) and includes both individual and higher level groupings of avian data, as well as small and large spatial ecological scales of site characteristics.

One goal of IBI development is to reduce the dimension of the problem to more manageable levels. For example, in Kimberling, et al, (2001), 57 invertebrate metrics were initially evaluated to measure human disturbance in the shrub-steppe region of Eastern Washington, of which only eight were used for the construction of the terrestrial IBI. Model 5 successfully follows this precedent, reducing the number of relevant avian metrics from 20 down to 8. Incorporation of multiple avian measures, in addition to a variety of site characteristics, provides strong improvement to the overall multivariate relationship. Table 3 summarizes the structure and results of all five scenarios. Guild based models do well, while diversity based models alone are not as complete. Combining the four scenarios into an overall integrated canonical model provides the strongest relationship between avian measures and site characteristics. Given these results, the avian measures selected for the integrated model were considered as good candidates for the construction of an A-IBI. 


\section{A-IBI Construction}

Before an IBI can be computed, the nature of the relationship between the selected variables and human disturbance must be determined, answering the question: does the selected biological measure increase or decrease with disturbance? Kerans and Karr (1994) suggest using expert opinion to determine the 'expected' direction, however, it is often difficult to find consensus among the experts. In addition, their recommendations may render contradictory results, and become subjective and unclear.

As an alternative, a multivariate approach can be used through either the sign of the respective canonical coefficients or through examination of the sign of the correlations between the biological variables and the site characteristic scores. Because site scores have been designed to measure human disturbance based on a consistent and common scale, the second method, based on correlations, provides a more logical and objective means for determining the specified response direction. Table 4 lists the correlations between the selected avian metrics and the corresponding site score measures. Summarizing across this table, the percentage of positive or negative correlations can be used to determine the direction of each avian response relative to human disturbance. Thus, five responses show an overall positive correlation, while the remaining three indicate a negative association.

Within each site, the selected avian responses are then individually scored into predetermined habitat integrity classes based on the direction of the response. Accordingly, the defined classes should have a sufficient range such that a good definition of the final IBI score may be obtained, while limiting the number of classes to avoid applying or implying too much precision to the problem. In this case, five classes were chosen: 1 - Very Low Integrity, 3 - Low Integrity, 5 - Moderate Integrity, 7 - High Integrity, and 9 - Very High Integrity. This is similar to classification definitions previously used by other researchers (see for example Karr et al, 1987; Fore and Karr, 1996). If the response distribution is symmetric, class assignment may be based on the response percentiles. When non-symmetric distributions are present, however, expert opinion may be necessary to determine class assignment. Figure 4 illustrates the distributions, IBI score categories and the assigned directions for the five positive and three negative avian responses. In this example, class assignments were carried out using distribution percentiles. It is important to note that the class assignment in IBI construction is rather subjective, and hence, the resulting measures of biotic integrity are only meant to be interpreted in relative terms among the available sites.

Following class assignment, the overall IBI score is computed by summing the scored avian responses within each site. Larger values of the IBI score represent higher levels of biotic integrity, while smaller values represent lower levels of biotic integrity. Table 5 presents the final A-IBI scores and the component class assignments for all avian sites. In addition, the canonical site score, rescaled from 1 to 10 , is also given. The IBI values range from a minimum of $8\left(8^{*} 1=8\right)$ to a potential maximum of 72 $(8 * 9=72)$. The observed minimum and maximum values for the A-IBI score in this case are 18 and 60 , respectively. These correspond to Site 5002, with an A-IBI=60, showing the highest avian integrity, and Site 7206 showing the lowest integrity. It is important to note that the aforementioned A-IBI values 
indicate the relative level of avian integrity, and do not measure an absolute level of integrity. Hence, one may conclude that one site is more suited for supporting the avian community compared to another site based on a higher value of A-IBI, but not that the specified site is optimal.

The correspondence between the avian IBI measures and the scaled canonical site score (indicating site characteristics) is shown in Figure 5. This relationship is strong $(\mathrm{R}=0.74)$ and positive, indicating that higher A-IBI values are associated with higher site integrity values. Hence, avian integrity follows site integrity reasonably well.

One means of visualizing the A-IBI values and their spatial arrangements is using a topographical map. Figure 6 gives a map for the A-IBI along the Kootenai River. Green colored sites indicate higher IBI values, while yellow and red colored sites denote moderate and low IBI values, respectively. It is evident that some clusters of sites have generally higher or lower avian integrity, however, no discernible spatial pattern in IBI values along the Kootenai River is noted. The clustering of IBI scores is not surprising due to the clustering of good or poor habitat conditions. Additionally, the apparent diverse spatial pattern could be related to the resiliency of vegetation communities buffering the impacts to hydraulic alterations.

\section{A-IBI Temporal Validation}

For the purposes of temporal A-IBI validation, data in years 2006 and 2010 collected at 54 sites which were in common with the 2007-2009 model building data were employed. Initially, the distributions of each avian response from the two data sets were compared based on a paired-t-test. Of the eight responses considered, only avian richness showed a significant difference in average value $(\mathrm{p}=$ 0.0057). This was mainly due to the higher abundance and diversity values observed in 2010. Overall, the avian responses in the combined 2006, 2010 dataset were similar to those of 2007-2009.

Given the above similarities, the final integrated canonical model, Model 5, was applied to the 2006, 2010 combined data. Figure 7 shows an overlaid plot of the primary canonical axis from the 20072009 data and the 2006, 2010 combined validation data. The observed positive trend from the original canonical analysis is also evident in the validation dataset. While the 2006, 2010 combined data do indicate some increase in variability, the patterns of the two datasets match very well.

As a final assessment of temporal validation, a set of A-IBI validation residuals was computed. Since a measure of IBI variability was unavailable, a bootstrap simulation procedure was used to compute the observed 2007-2009 simulated A-IBI values, assuming years as replication. For each observation site, three observations for each avian response were uniformly selected with replacement from the available years. These responses were then averaged and scored as described above to form a bootstrap A-IBI value. A residual IBI value was then formed from the difference as: A-IBI $2006,2010-\mathrm{A}-\mathrm{IBI}_{\mathrm{Bootstrap}}$. The process was repeated $\mathrm{B}=1000$ times and the resulting residual IBI values were evaluated. A plot of the residuals over site (arranged from downstream to upstream) is shown in Figure 8. Although a slight trend is evident, the overall pattern is random and indicates no systematic differences from the 2007-2009 
values. Also, the mean residual value was not significantly different from zero $(p=0.2949)$. Therefore, the A-IBI values appear to be temporally stable within the specified time frame.

\section{A-IBI Spatial Validation}

For the purposes of spatial validation, 31 additional independent avian sites available from the 2007-2009 time period were used. As with the temporal validation, the distributions of the selected avian measures were compared for the two data sets. No significant differences in avian response averages were found ( $p>0.05)$. While a direct comparison to the original A-IBI values is not possible (the data sets do not encompass matching sites) the average computed IBI values of the two sets were similar. Hence, the A-IBI values validated well with independent sites within the same time frame. Additional onsite ground truthing will be necessary to provide further verification of these A-IBI values.

\section{Concluding Remarks}

The multivariate analyses of the avian data provided an enhanced IBI methodology and produced reasonable IBI scores for the specified avian sites within the project. The selected avian responses

provided both lower and higher level representations of avian data. The final consolidated model and the associated A-IBI scores were statistically verified and validated using additional sites and years, and produced reliable results. The A-IBI values showed a strong correlation to the scaled canonical site score indicating a good representation of avian site integrity. Future work will utilize available project invertebrate data by applying the same statistical techniques and IBI methodology. Subsequently, it will be instructive to compare and contrast the A-IBI scores with the corresponding terrestrial Invertebrate Index of Biotic Integrity (I-IBI) scores for the same sites, thus providing a more comprehensive account of overall site integrity along the Kootenai River.

\section{Acknowledgement}

The authors would like to thank the Kootenai Tribe of Idaho for managing and coordinating the Operational Loss Project, the Montana Fish, Wildlife and Parks for ensuring data collection quality, and the Bonneville Power Administration for provision of funding.

\section{References}

J. K. Andreasen, R. V. O’Neill, R. Noss, and N. C. Slosser. 2001. Considerations for the development of a terrestrial index of ecological integrity. Ecological Indicators 1: 21-35.

E.C.Pielou. 1977. Mathematical ecology. Wiley-Interscience Publ., NY. 385pp. 
Environmental System Research Institute (ESRI) 2002. ArcGIS 8.3. Redlands, California.

L. S. Fore and J. R. Karr. 1996. Assessing invertebrate responses to human activities: evaluating alternative approaches. Journal of North America Benthological Society 15(2): 212-231.

M. O Hill. (1973). Diversity and evenness: a unifying notation and its consequences. Ecology, 54, 427432.

F. C. James and C. E. McCulloch. 1990. Multivariate analysis in ecology and systematics. Annual review of Ecology and Systematics 21:129-166.

J. R. Karr. 1999. Defining and measuring river health. Freshwater Biology 41: 221-234.

J. R. Karr, P. R. Yant, and K. D. Fausch. 1987. Spatial and temporal variability of the index of biotic integrity in three Midwestern streams. Transactions of the American Fisheries Society 116:1-11.

B. L. Kerans and J. R. Karr. 1994. A benthic index of biotic integrity (B-IBI) for the rivers of the Tennessee valley. Ecological Applications 4(4): 768-785.

D. N. Kimberling , J. R. Karr and L. S. Fore. 2001. Measuring human disturbance using terrestrial invertebrates in the shrub-steppe of eastern Washington (USA). Ecological Indicators 1: 63-81.

B.G.Marcot and M.Vander Heyden. 2001. Chapter 6: Key ecological functions of wildlife species. Pages 168-186 in D.H.Johnson and T.A.O’Neil. 2001, Managing Directors. Oregon State University Press, Corvaillis, OR. 736pp.

D. F. Morrison. 1976. Multivariate Statistical Methods. Second Edition. McGraw-Hill Book Company, New York, USA.

U.S. EPA. 2002. Methods for evaluating wetland condition: Biological assessment methods for birds. EPA-822-R-02-023, EPA Office of Water, Washington, DC. 
(A) Model 1

\begin{tabular}{|c|c|}
\hline Avian Metric & Coefficient \\
\hline Richness & -1.09 \\
\hline Hill N2 & 1.02 \\
\hline $\mathrm{N}_{2} / \mathrm{N}_{1}$ & -0.29 \\
\hline $\operatorname{In}($ Count) & -0.67 \\
\hline
\end{tabular}

\begin{tabular}{|c|c|}
\hline $\begin{array}{c}\text { Hydrology } \\
\text { Measure }\end{array}$ & Coefficient $\mathbf{R}=\mathbf{0 . 6 7}$ \\
\hline WD_Avg & 0.60 \\
\hline FD_Avg & 0.98 \\
\hline SS_Avg & -0.33 \\
\hline FFZ & -0.68 \\
\hline
\end{tabular}

(B) Model 2

\begin{tabular}{|c|c|}
\hline Avian Guild & Coefficient \\
\hline Avg_KEF & -0.26 \\
\hline Redund KEF & -0.17 \\
\hline Resident & 0.5313 \\
\hline Beneficial & -0.3471 \\
\hline Sensitive & 0.2758 \\
\hline Dependent & 0.7029 \\
\hline Neutral Nest & 0.3691 \\
\hline
\end{tabular}

\begin{tabular}{|c|c|}
\hline $\begin{array}{c}\text { Hydrology } \\
\text { Measure }\end{array}$ & Coefficient \\
\hline WD_Avg & 0.71 \\
\hline FD_Avg & 0.33 \\
\hline SS_Avg & -0.92 \\
\hline
\end{tabular}

(C) Model 3

\begin{tabular}{|c|c|}
\hline Avian Metric & Coefficient \\
\hline Richness & -1.40 \\
\hline Hill N2 & 1.94 \\
\hline $\mathrm{N}_{2} / \mathrm{N}_{1}$ & -1.32 \\
\hline $\operatorname{In}($ Count) & -0.91 \\
\hline
\end{tabular}

\begin{tabular}{|c|c|}
\hline $\begin{array}{c}\text { Vegetation } \\
\text { Measure }\end{array}$ & Coefficient \\
\hline Struct & 0.77 \\
\hline RCG & 0.65 \\
\hline RIP & -0.13 \\
\hline
\end{tabular}

(D) Model 4

\begin{tabular}{|c|c|}
\hline Avian Guild & Coefficient \\
\hline Redund KEF & 0.23 \\
\hline Short distance & 0.45 \\
\hline Mexico & -0.34 \\
\hline Sensitive & 0.85 \\
\hline Marsh & -0.68 \\
\hline
\end{tabular}

\begin{tabular}{|c|c|}
\hline $\begin{array}{c}\text { Vegetation } \\
\text { Measure }\end{array}$ & Coefficient \\
\hline Struct & $\mathbf{0 . 6 9}$ \\
\hline Tree & 0.33 \\
\hline RCG & 0.03 \\
\hline RIP & 0.06 \\
\hline
\end{tabular}

Table 1. Final reduced canonical models for four avian, site characteristic scenarios: A) avian metrics and hydrologic scores, B) avian guild and hydrologic scores, C) avian metric and vegetative scores, and avian guild and vegetative scores. Only the coefficients and correlations for the first canonical axes are shown. 


\begin{tabular}{|r|c|c|c|c|}
\hline Axis & $\begin{array}{c}\text { Canonical } \\
\text { Correlation }\end{array}$ & Eigenvalue & Proportion & p-value \\
\hline 1 & 0.8904 & 3.82 & 0.69 & 0.0001 \\
\hline 2 & 0.6651 & 0.79 & 0.83 & 0.0179 \\
\hline 3 & 0.6471 & 0.72 & 0.96 & 0.0368 \\
\hline 4 & 0.318 & 0.11 & 0.98 & 0.7553 \\
\hline 5 & 0.2381 & 0.06 & 0.99 & 0.6818 \\
\hline
\end{tabular}

Model 5

\begin{tabular}{|c|c|}
\hline Avian Metric & Coefficient \\
\hline Richness & -1.34 \\
\hline Hill N2 & 1.40 \\
\hline $\mathrm{N}_{2} / \mathrm{N}_{1}$ & -0.69 \\
\hline Avg KEF & -0.30 \\
\hline Resident & 0.34 \\
\hline Short Distance & 0.24 \\
\hline Sensitive & 0.31 \\
\hline Dependent & 0.63 \\
\hline
\end{tabular}

\begin{tabular}{|c|c|}
\hline $\begin{array}{c}\text { Site } \\
\text { Measure }\end{array}$ & Coefficient \\
\hline WD_Avg & 0.89 \\
\hline FD_Avg & 0.47 \\
\hline SS_Avg & -0.55 \\
\hline Tree & 0.61 \\
\hline RCG & 0.48 \\
\hline RIP & -0.39 \\
\hline
\end{tabular}

Table 2. The final integrated canonical model for avian metrics and guild measures as a function of hydrologic and vegetative site scores. Only the coefficients and correlation for the first axis are shown. 


\begin{tabular}{|c|c|c|c|c|c|c|c|}
\cline { 3 - 8 } \multicolumn{2}{c|}{} & \multicolumn{4}{c|}{ Number of Final Components } & \multicolumn{2}{c|}{ Canonical Correlations } \\
\hline Model & Description & Metrics & Guilds & Hydrologic & Vegetation & Full Model & Red. Model \\
\hline Model 1 & Hydro - Metrics & 3 & & 4 & & 0.70 & 0.67 \\
\hline Model 2 & Hydro - Guild & & 7 & 3 & & 0.73 & 0.71 \\
\hline Model 3 & Veg - Metrics & 4 & & & 3 & 0.78 & 0.65 \\
\hline Model 4 & Veg - Guild & & 5 & & 4 & 0.77 & 0.75 \\
\hline Model 5 & Integrated & 3 & 5 & 3 & 3 & 0.93 & 0.89 \\
\hline
\end{tabular}

Table 3. Summary table for the full and reduced canonical models for the four model scenarios and the final integrated model.

\begin{tabular}{|c|c|c|c|c|c|c|c|c|}
\hline & \multirow[b]{2}{*}{ WD_Avg } & \multirow[b]{2}{*}{ FD_Avg } & \multirow[b]{2}{*}{ SS_Avg } & \multirow[b]{2}{*}{ Tree } & \multirow[b]{2}{*}{ RCG } & \multirow[b]{2}{*}{ Rip } & \multicolumn{2}{|c|}{ Metric Direction } \\
\hline & & & & & & & $\% \quad(+)$ & $\%$ \\
\hline Richness & -0.28 & -0.20 & -0.11 & 0.26 & -0.06 & 0.20 & 33.33 & 66.67 \\
\hline Hill_N2 & -0.03 & 0.02 & -0.11 & 0.32 & 0.11 & 0.24 & 66.67 & 33.33 \\
\hline N2_N1 & 0.34 & 0.31 & -0.01 & 0.07 & 0.10 & -0.05 & 66.67 & 33.33 \\
\hline Avg KEF & -0.19 & -0.18 & -0.09 & -0.06 & -0.03 & 0.09 & 16.67 & 83.33 \\
\hline Resident & 0.15 & 0.17 & -0.13 & 0.15 & 0.29 & 0.18 & 83.33 & 16.67 \\
\hline Short_distance & -0.04 & -0.14 & -0.08 & -0.06 & -0.07 & -0.16 & 0.00 & 100.00 \\
\hline Sensitive & 0.00 & 0.04 & 0.01 & 0.43 & 0.07 & 0.41 & 100.00 & 0.00 \\
\hline Dependent & 0.30 & 0.30 & -0.10 & 0.29 & 0.28 & 0.25 & 83.33 & 16.67 \\
\hline
\end{tabular}

Positive Correlation
Negative Correlation

Table 4. Correlations among the selected avan responses and the hydrologic and vegetative site scores. Five responses indicate a positive overall association, while three display a negative association. 


\begin{tabular}{|c|c|c|c|c|c|c|c|c|c|c|}
\hline Site & Richness & Hill N2 & N2/N1 & Avg KEF & Resident & Short Dist & Sensitive & Dependent & IBI & $\begin{array}{c}\text { Site } \\
\text { Rank }\end{array}$ \\
\hline 1018 & 3 & 7 & 9 & 7 & 7 & 7 & 5 & 5 & 50 & 5.1 \\
\hline 1023 & 7 & 5 & 7 & 9 & 1 & 3 & 5 & 1 & 38 & 5.1 \\
\hline 1078 & 9 & 3 & 9 & 7 & 5 & 3 & 1 & 7 & 44 & 4.6 \\
\hline 1089 & 3 & 9 & 9 & 7 & 3 & 1 & 5 & 5 & 42 & 5.7 \\
\hline 1093 & 3 & 9 & 7 & 5 & 9 & 3 & 5 & 7 & 48 & 5.0 \\
\hline 1128 & 1 & 9 & 5 & 3 & 1 & 3 & 9 & 7 & 38 & 6.1 \\
\hline 1135 & 3 & 7 & 5 & 7 & 3 & 1 & 5 & 3 & 34 & 7.5 \\
\hline 1138 & 7 & 5 & 7 & 9 & 3 & 1 & 7 & 1 & 40 & 5.9 \\
\hline 1185 & 5 & 5 & 5 & 3 & 5 & 1 & 5 & 3 & 32 & 5.4 \\
\hline 1189 & 1 & 9 & 7 & 1 & 3 & 9 & 9 & 7 & 46 & 5.3 \\
\hline 2052 & 5 & 7 & 9 & 3 & 7 & 3 & 7 & 5 & 46 & 5.7 \\
\hline 4005 & 3 & 7 & 5 & 3 & 5 & 1 & 7 & 5 & 36 & 5.1 \\
\hline 4029 & 3 & 7 & 7 & 3 & 9 & 7 & 1 & 3 & 40 & 6.4 \\
\hline 5002 & 9 & 5 & 9 & 9 & 5 & 9 & 9 & 5 & 60 & 6.6 \\
\hline 5037 & 7 & 3 & 3 & 9 & 3 & 9 & 3 & 1 & 38 & 3.2 \\
\hline 5051 & 3 & 1 & 1 & 7 & 1 & 5 & 3 & 5 & 26 & 5.9 \\
\hline 5053 & 9 & 3 & 7 & 5 & 3 & 1 & 1 & 9 & 38 & 4.5 \\
\hline 5060 & 7 & 5 & 7 & 1 & 3 & 1 & 3 & 9 & 36 & 6.3 \\
\hline 5074 & 9 & 3 & 9 & 5 & 9 & 3 & 7 & 3 & 48 & 7.4 \\
\hline 5085 & 3 & 5 & 3 & 5 & 3 & 7 & 5 & 5 & 36 & 5.0 \\
\hline 5141 & 9 & 1 & 9 & 3 & 9 & 9 & 1 & 7 & 48 & 4.2 \\
\hline 5147 & 9 & 3 & 7 & 1 & 7 & 7 & 5 & 7 & 46 & 6.7 \\
\hline 6010 & 3 & 1 & 1 & 3 & 7 & 3 & 3 & 9 & 30 & 6.4 \\
\hline 6018 & 3 & 7 & 3 & 1 & 7 & 7 & 9 & 3 & 40 & 5.2 \\
\hline 6066 & 3 & 3 & 3 & 1 & 3 & 7 & 1 & 9 & 30 & 7.1 \\
\hline 6181 & 1 & 9 & 5 & 5 & 7 & 7 & 9 & 5 & 48 & 6.4 \\
\hline 6183 & 7 & 1 & 1 & 9 & 3 & 5 & 1 & 3 & 30 & 3.9 \\
\hline 6195 & 1 & 9 & 7 & 3 & 7 & 3 & 5 & 9 & 44 & 5.4 \\
\hline 6197 & 1 & 9 & 7 & 9 & 5 & 1 & 7 & 5 & 44 & 5.9 \\
\hline 6201 & 1 & 9 & 7 & 9 & 5 & 7 & 9 & 5 & 52 & 8.5 \\
\hline 6202 & 7 & 5 & 3 & 7 & 7 & 9 & 9 & 7 & 54 & 8.2 \\
\hline 6203 & 5 & 7 & 9 & 5 & 9 & 5 & 7 & 9 & 56 & 9.1 \\
\hline 6204 & 1 & 9 & 9 & 5 & 7 & 5 & 7 & 7 & 50 & 7.3 \\
\hline 6205 & 5 & 7 & 9 & 1 & 9 & 7 & 9 & 9 & 56 & 7.9 \\
\hline 7005 & 3 & 3 & 3 & 1 & 1 & 7 & 9 & 1 & 28 & 3.1 \\
\hline 7014 & 3 & 5 & 3 & 1 & 1 & 9 & 9 & 1 & 32 & 2.2 \\
\hline 7025 & 5 & 5 & 3 & 1 & 1 & 3 & 7 & 1 & 26 & 2.0 \\
\hline 7103 & 3 & 1 & 1 & 9 & 1 & 1 & 9 & 1 & 26 & 3.1 \\
\hline 7107 & 1 & 3 & 1 & 1 & 5 & 3 & 3 & 1 & 18 & 1.0 \\
\hline 7108 & 7 & 3 & 3 & 5 & 1 & 5 & 7 & 1 & 32 & 2.0 \\
\hline 7205 & 7 & 1 & 1 & 3 & 7 & 9 & 3 & 3 & 34 & 2.9 \\
\hline 7206 & 9 & 1 & 3 & 1 & 1 & 1 & 1 & 1 & 18 & 2.4 \\
\hline 7207 & 1 & 9 & 1 & 5 & 5 & 5 & 7 & 5 & 38 & 5.0 \\
\hline 7208 & 3 & 9 & 5 & 7 & 5 & 9 & 9 & 7 & 54 & 7.4 \\
\hline 7301 & 3 & 5 & 3 & 5 & 7 & 9 & 5 & 7 & 44 & 5.7 \\
\hline 7304 & 1 & 7 & 3 & 7 & 5 & 5 & 5 & 3 & 36 & 4.5 \\
\hline 7306 & 1 & 7 & 1 & 7 & 9 & 7 & 7 & 3 & 42 & 4.9 \\
\hline 7308 & 3 & 7 & 5 & 5 & 1 & 5 & 3 & 3 & 32 & 2.8 \\
\hline 8004 & 7 & 1 & 1 & 9 & 3 & 5 & 1 & 9 & 36 & 6.5 \\
\hline 8022 & 7 & 5 & 5 & 7 & 3 & 7 & 1 & 9 & 44 & 5.0 \\
\hline 8103 & 1 & 9 & 1 & 3 & 5 & 3 & 7 & 7 & 36 & 4.4 \\
\hline 8407 & 7 & 3 & 5 & 7 & 9 & 5 & 1 & 3 & 40 & 8.0 \\
\hline 8413 & 9 & 3 & 5 & 3 & 7 & 1 & 3 & 3 & 34 & 9.0 \\
\hline 8418 & 9 & 3 & 9 & 9 & 9 & 1 & 3 & 9 & 52 & 10.0 \\
\hline 8421 & 9 & 1 & 7 & 1 & 9 & 5 & 3 & 9 & 44 & 6.5 \\
\hline 8512 & 5 & 1 & 1 & 3 & 9 & 9 & 3 & 1 & 32 & 5.8 \\
\hline 8521 & 3 & 7 & 5 & 7 & 9 & 3 & 3 & 7 & 44 & 6.0 \\
\hline 8654 & 9 & 1 & 9 & 9 & 1 & 9 & 1 & 9 & 48 & 5.7 \\
\hline
\end{tabular}

Table 5. The computed A-IBI values for all sites along with their component IBI classifications and the corresponding scaled canonical site score. 


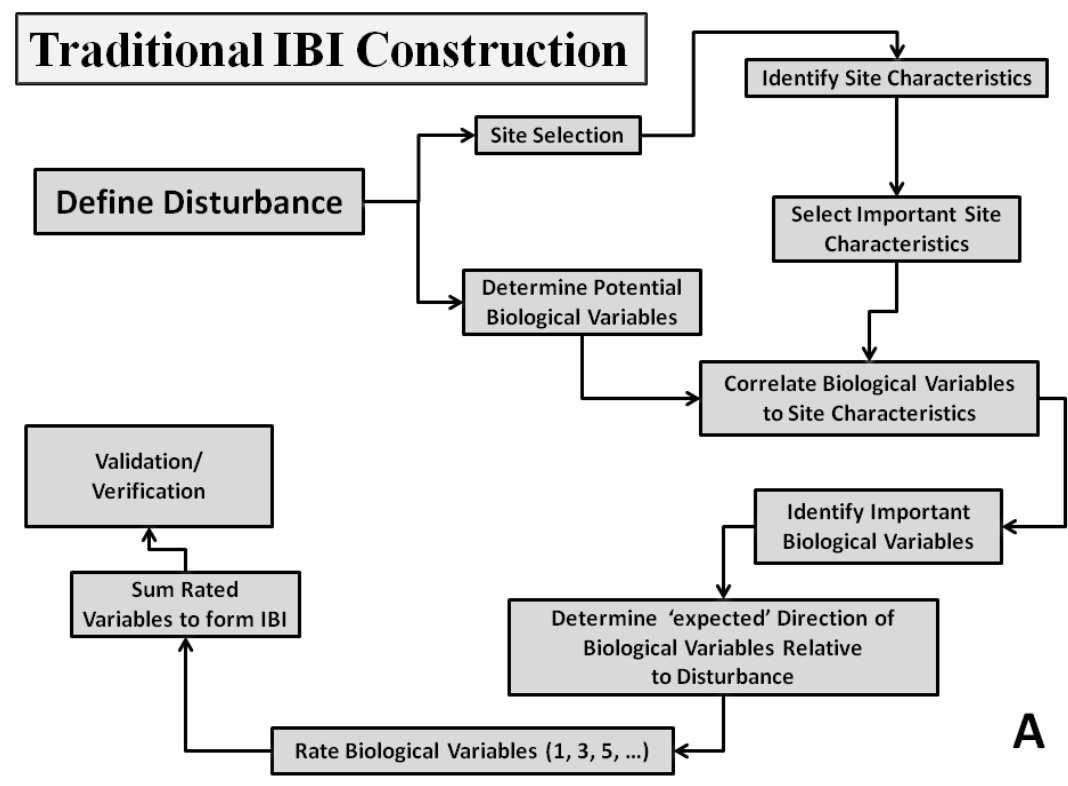

\section{Enhanced IBI Construction}

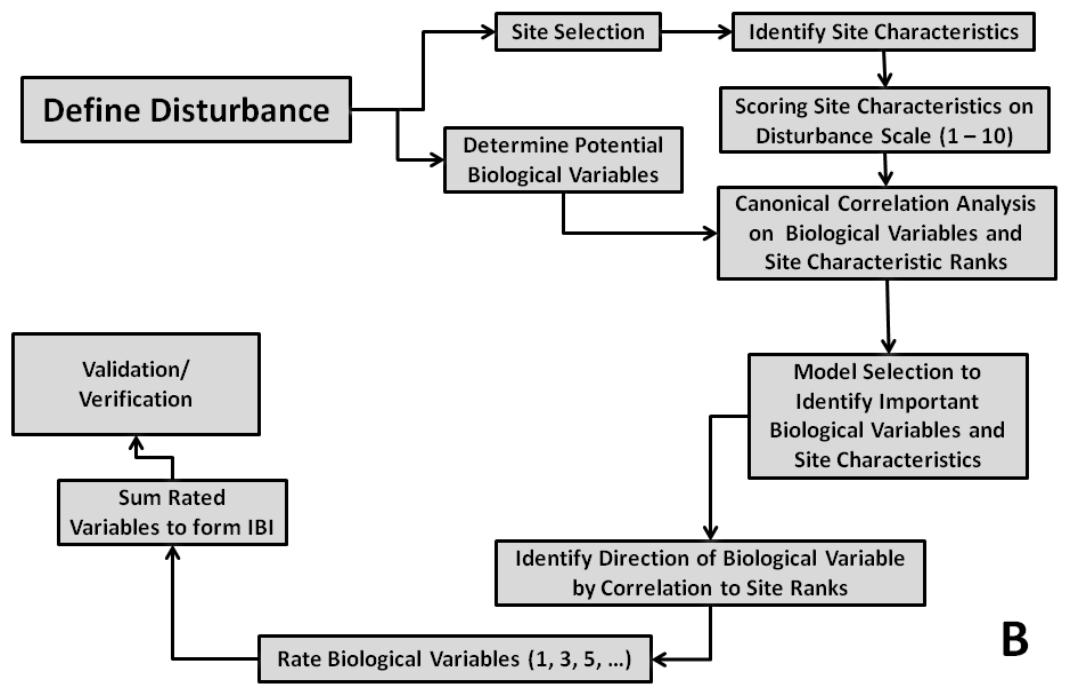

Figure 1. The traditional $(\mathrm{A})$ and enhanced (B) flow charts for IBI construction. 


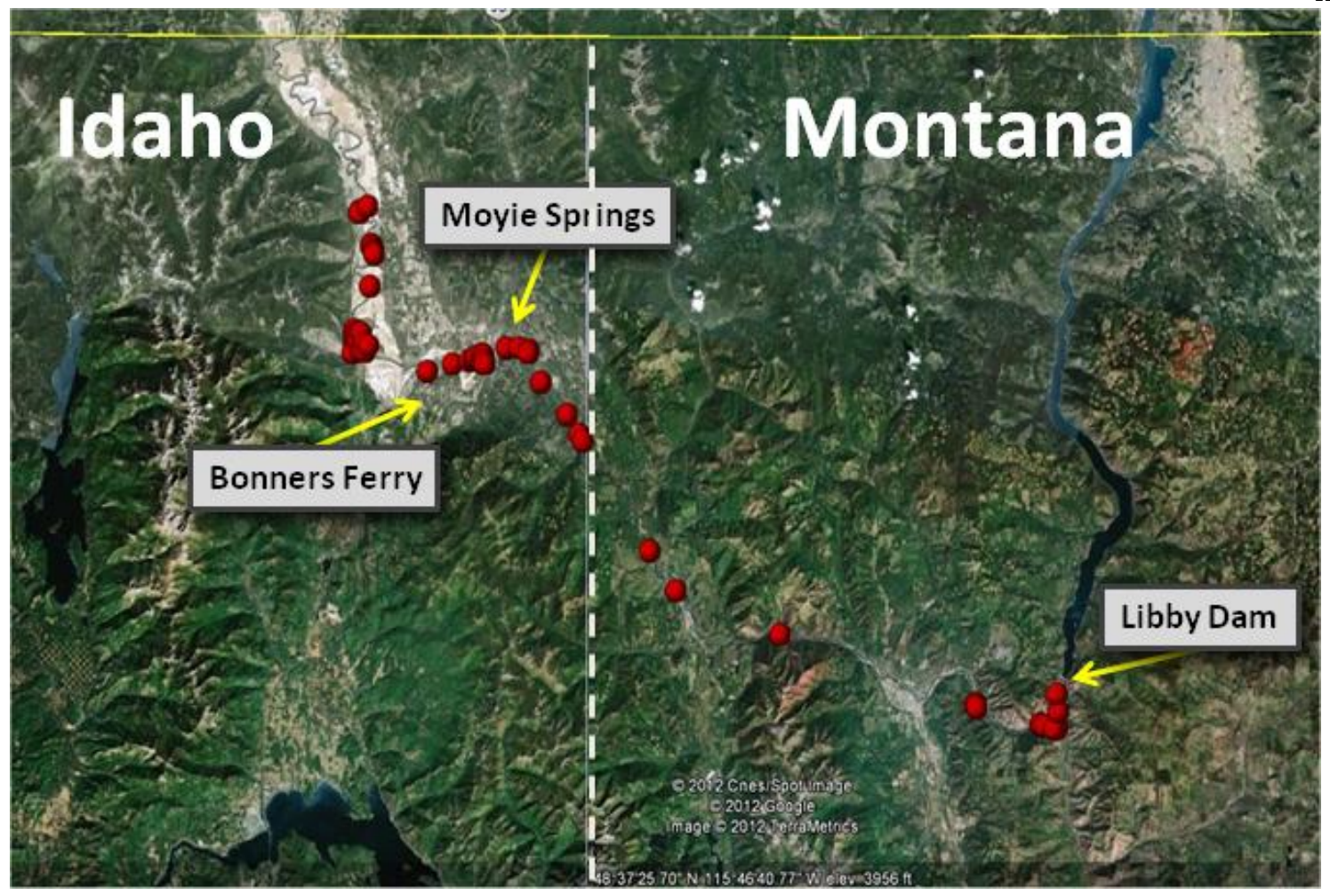

Figure 2. The 58 avian sampling sites located along the Kootenai River in Idaho and Montana.

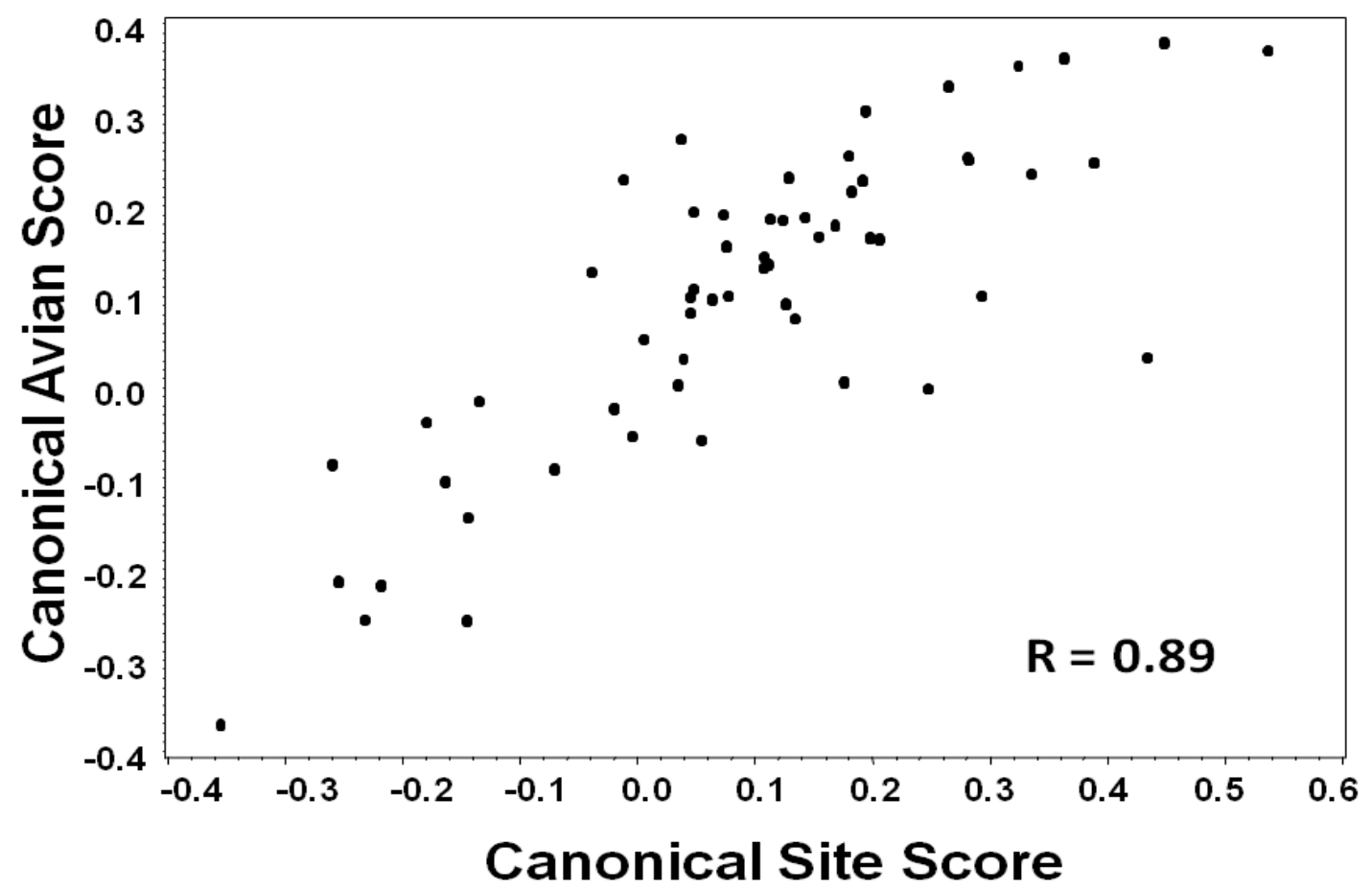

Figure 3. The primary canonical relationship between avian responses and hydrologic and vegetative site characteristic scores. 
A
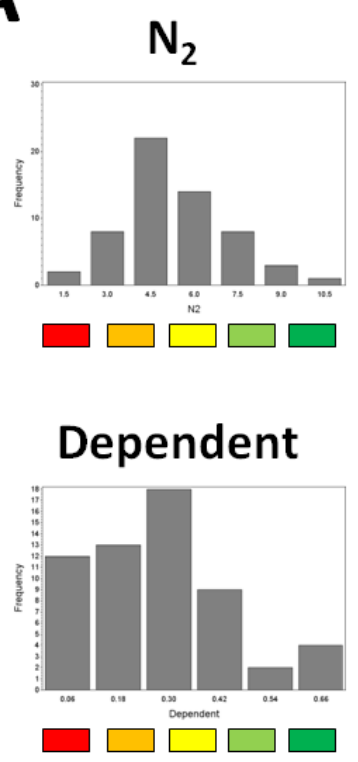

B

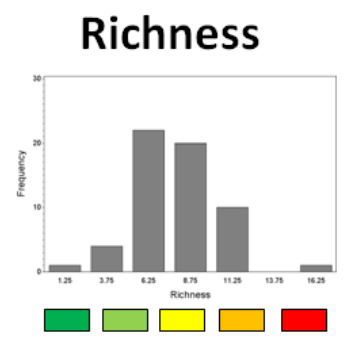

Sensitive

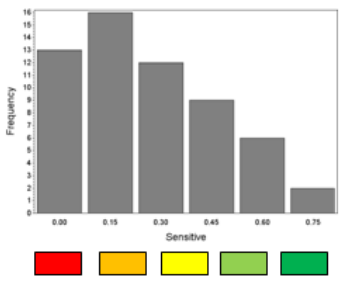

\section{Resident}

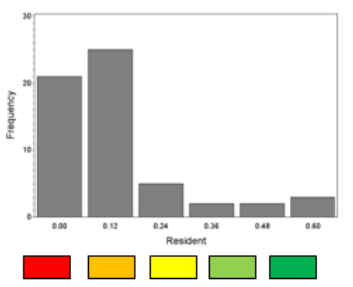

1: Very Low Integrity

3: Low Integrity

5: Moderate Integrity

7: High Integrity

9: Very High Integrity

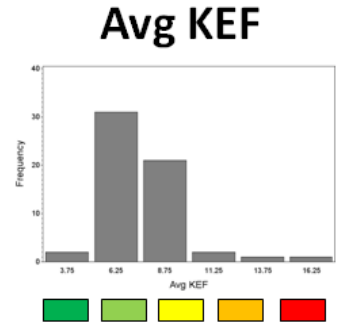

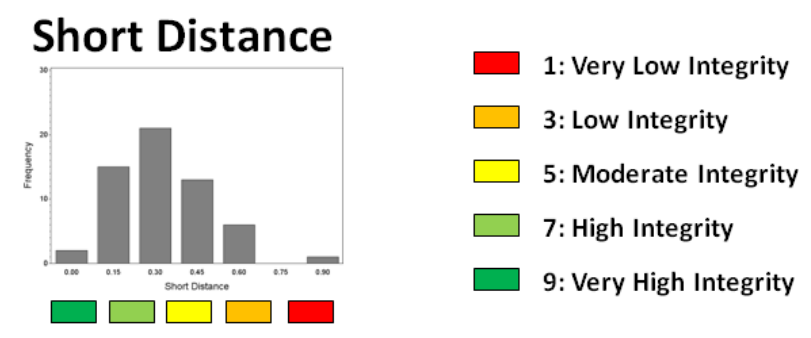

Figure 4. Response distributions for the eight selected avian responses. Five measures were positively associated with site scores $(A)$ and three were negatively associated with site scores (B). 


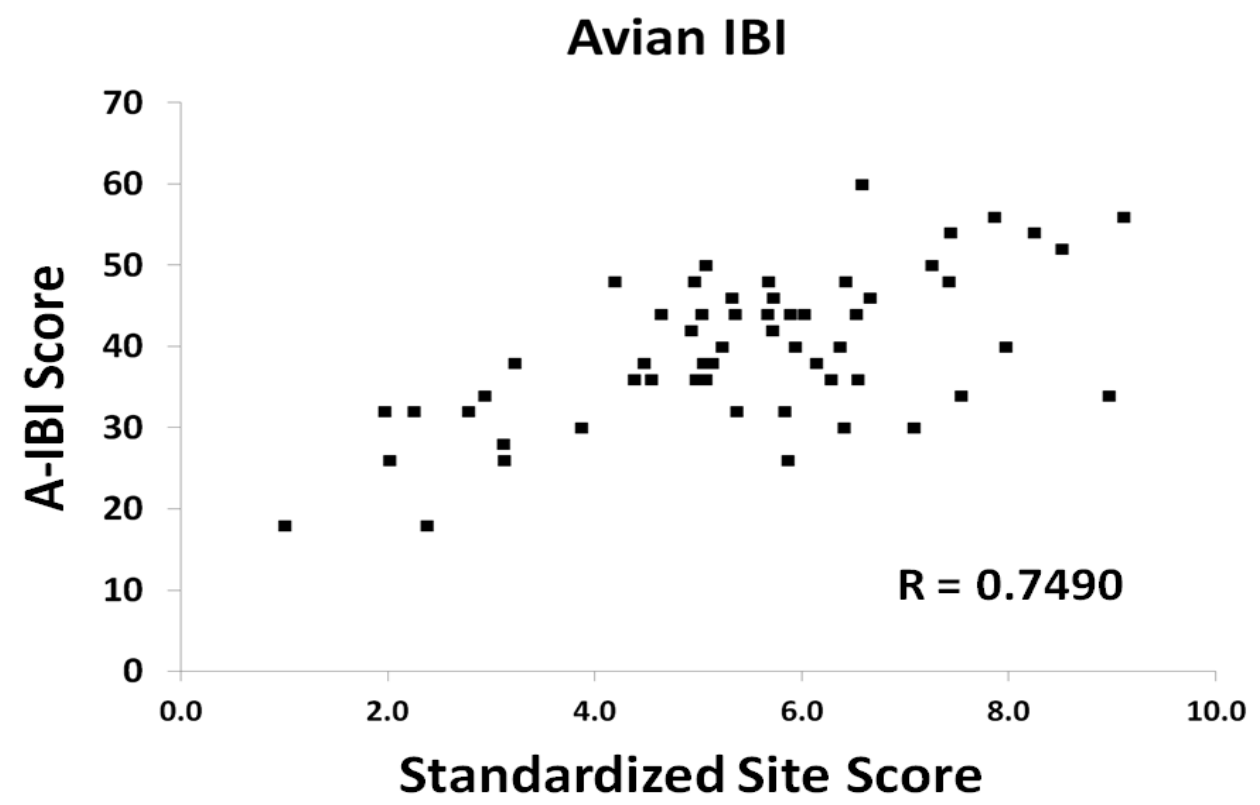

Figure 5. The association between the computed avian IBI (A-IBI) and the standardized canonical site scores.

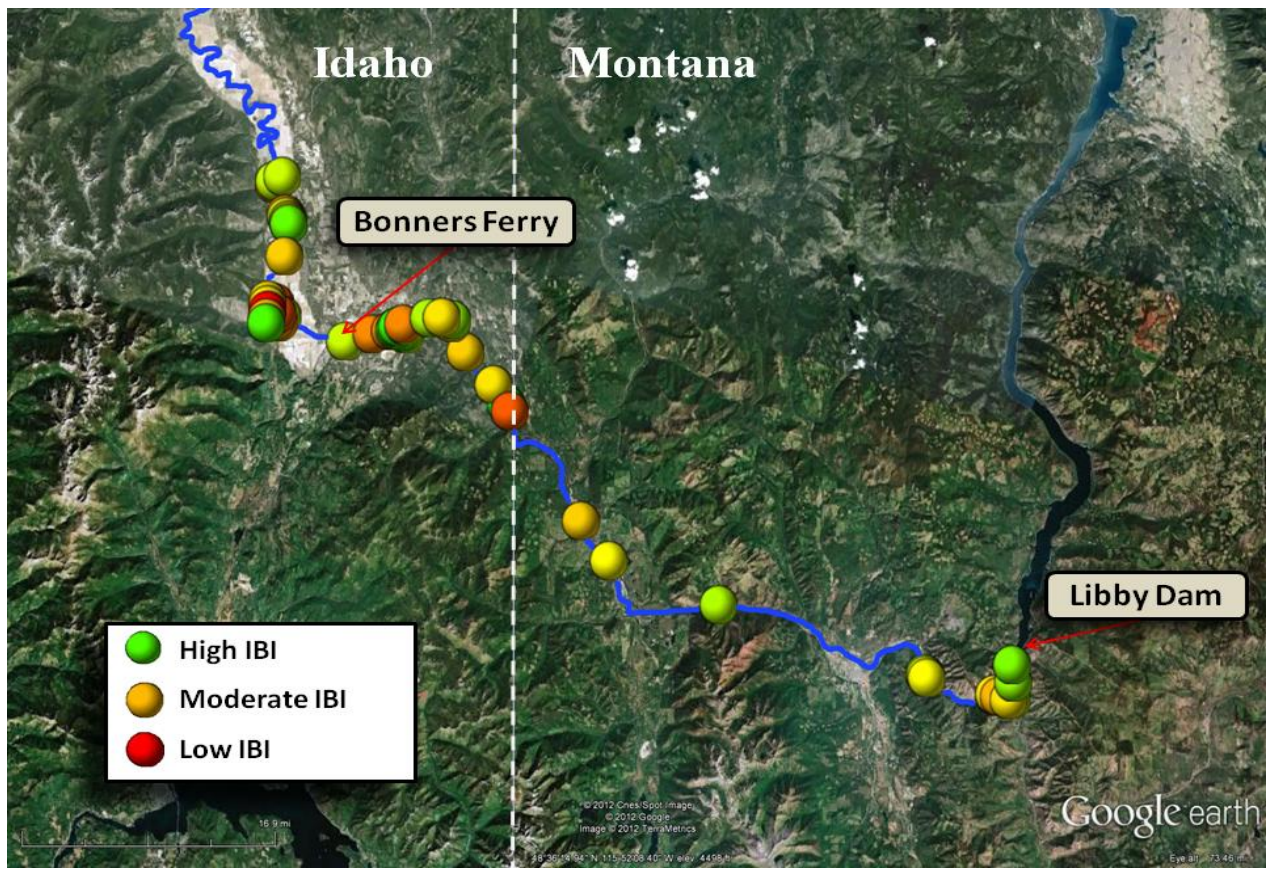

Figure 6. Graphical representation of A-IBI intensity along the Kootenai River. Green markers indicate high A-IBI values, yellow represent moderate A-IBI values and red markers show low A-IBI values. 


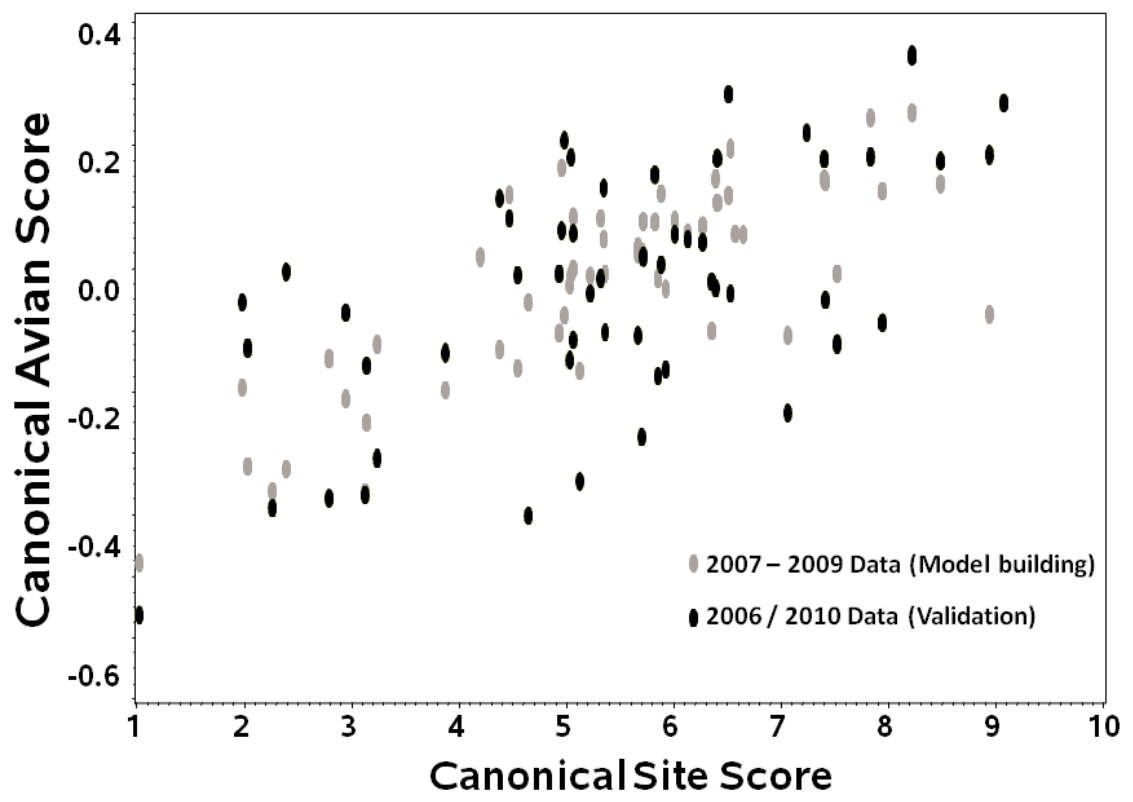

Figure 7. Comparison of the canonical relationship of the 2007-2009 data (gray dots) and the 2006, 2010 data (black dots).

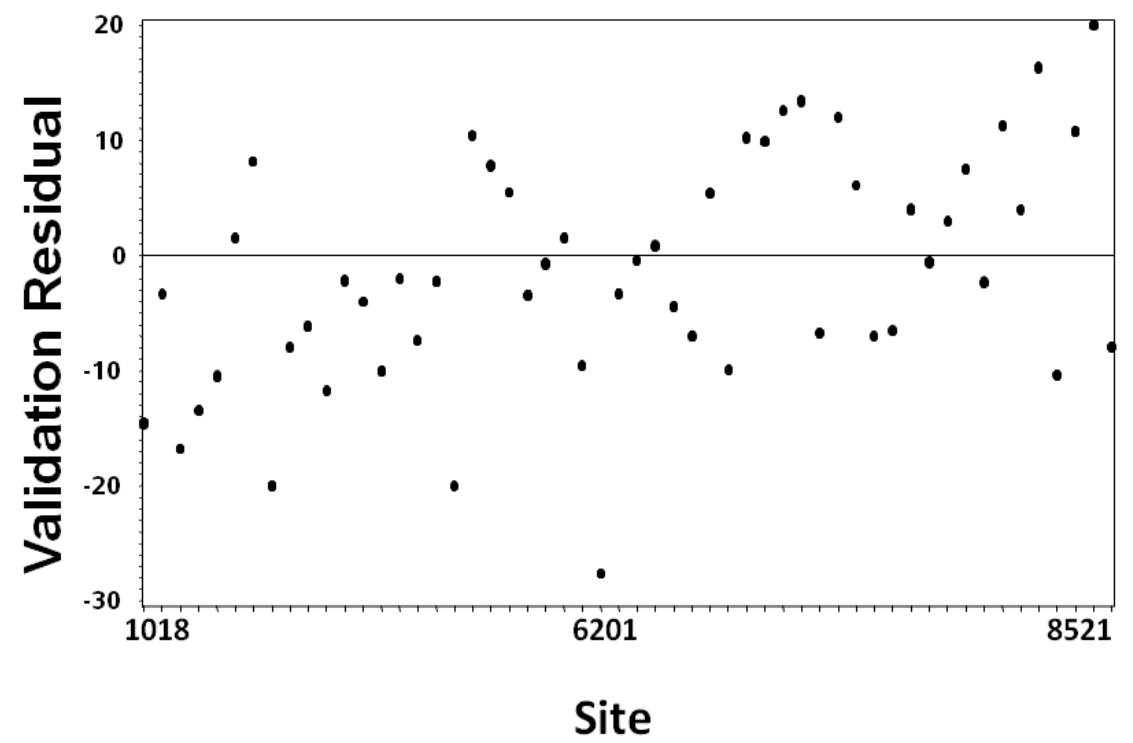

Downstream

$\underset{\text { Upstream }}{\longrightarrow}$

Figure 8. Temporal A-IBI validation residuals plotted versus sampling site ID arranged in spatial order along the Kootenai River. 